Pesq. Vet. Bras. 38(5):835-839, maio 2018

DOI: $10.1590 / 1678-5150-P V B-5408$

(c)) EY-NC

\title{
Plantas tóxicas para ruminantes e equídeos do estado de Sergipe ${ }^{1}$
}

\author{
Eduardo M. Nascimento ${ }^{2 *}$, Rosane M.T. Medeiros ${ }^{2}$ e Franklin Riet-Correa ${ }^{2,3}$
}

\begin{abstract}
Nascimento E.M., Medeiros R.M.T. \& Riet-Correa F. 2018. [Toxic plants for ruminants and equidae in the state of Sergipe, Brazil.] Plantas tóxicas para ruminantes e equídeos do estado de Sergipe. Pesquisa Veterinária Brasileira 38(5):835-839. Laboratório de Patologia Animal, Unidade Acadêmica de Medicina Veterinária, Centro de Saúde e Tecnologia Rural, Universidade Federal de Campina Grande, Avenida Universitária s/n, Patos, PB 58700-970, Brazil. E-mail: eduardoaquario@hotmail.com

In a survey on toxic plants for ruminants and equidae conducted in 2015 and 2016 in the state of Sergipe, farms from 16 municipalities of different microregions (litoral, agreste and sertão) were visited. Thirty two farmers and 10 veterinarians were interviewed about the occurrence of known toxic plants in the state of Sergipe and poisoning by plants previously unknown. According to the survey, Amorimia spp., Crotalaria retusa, Ipomoea asarifolia, Palicourea aeneofusca and Poiretia punctata are important causes of death on livestock in the region. Sporadic poisonings by Ipomoea carnea subsp. fistulosa, Mimosa tenuiflora, Pannisetum purpureum and Manihot esculenta were also registered. Some farmers reported poisoning by Ziziphus joazeiro and Citrus spp., which had not been reported previously as toxic.
\end{abstract}

INDEX TERMS: Poisonous plants, ruminants, equidae, plant poisoning, toxic plants, Sergipe, Brazil, toxicoses.

RESUMO.- Em um levantamento feito nos anos de 2015 e 2016 no estado de Sergipe, com o objetivo de conhecer as plantas tóxicas para ruminantes e equídeos, foram visitadas propriedades rurais em 16 municípios, englobando as mesorregiões do litoral, agreste e sertão. Para isso foram realizadas entrevistas a 32 produtores e 10 a médicos veterinários da região. De acordo com o levantamento, Amorimia spp., Crotalaria retusa, Ipomoea asarifolia, Palicourea aeneofusca e Poiretia punctata são responsáveis por mortes de animais gerando prejuízos consideráveis aos produtores. Surtos esporádicos de intoxicações por Ipomoea carnea subsp. fistulosa, Mimosa tenuiflora, Pannisetum purpureum e Manihot esculenta também foram relatados. Alguns produtores relataram surtos isolados de intoxicações por Ziziphus joazeiro e citrus sp, plantas não conhecidas anteriormente como tóxicas.

\footnotetext{
${ }^{1}$ Recebido em 4 de maio de 2017.

Aceito para publicação em 25 de maio de 2017.

Pesquisa de doutorado com apoio CNPq.

${ }^{2}$ Laboratório de Patologia Animal, Unidade Acadêmica de Medicina Veterinária, Centro de Saúde e Tecnologia Rural, Universidade Federal de Campina Grande, (UFCG), Av. Universitária s/n, Patos, PB 58700-970, Brasil.

*Autor para correspondencia: eduardoaquario@hotmail.com

${ }^{3}$ Nationa Institute for Agricultural Research, INIA La Estanzuela, CP 70.000, Colonia, Uruguay.
}

TERMOS DE INDEXAÇÃO: Plantas tóxicas, ruminantes, equídeos, intoxicação por plantas, Sergipe, toxicoses.

\section{INTRODUÇÃO}

No Brasil, foram descritas cerca de 130 espécies de plantas tóxicas (Tokarnia et al. 2012), responsáveis por perdas econômicas significativas para os produtores rurais, que vão desde gastos com a construção de cercas para isolamento de áreas, diminuição do ganho ou perda de peso, menores taxas reprodutivas, abortos e morte de animais (Riet-Correa \& Medeiros 2001, Pessoa et al. 2013).

0 estudo de plantas tóxicas em estados com poucas pesquisas na área é de fundamental importância para conhecer as intoxicações e diminuir as perdas econômicas. Um exemplo marcante é o estado da Paraíba, que após a implantação de um grupo de pesquisa em plantas tóxicas passou de 8 para 21 plantas conhecidas como tóxicas para animais de produção (Riet-Correa et al. 2006a).

Mesmo com o extensivo estudo e vasta literatura relacionada às plantas tóxicas do Brasil (Riet-Correa et al. 2009, Tokarnia et al. 2012), ainda há carência de informações relacionadas à frequência de intoxicações causadas por plantas em algumas regiões do país (Tokarnia et al. 2012, Pessoa et al. 2013). Conhecendo-se a epidemiologia e ocorrência das intoxicações, medidas de controle podem ser tomadas evitando 
ou minimizando problemas. Pelo fato de não haver estudos que mensurem os problemas causados por plantas tóxicas no estado de Sergipe, objetiva-se com esse trabalho relatar a ocorrência das plantas tóxicas conhecidas que ocorrem no estado de Sergipe e relatar novos casos em que plantas são apontadas como causadoras dos problemas.

\section{MATERIAL E MÉTODOS}

O trabalho foi realizado em 16 municípios do estado de Sergipe (Fig.1) abrangendo as três mesorregiões do estado: litoral, agreste e sertão. Na mesorregião do sertão foram visitados os municípios de Poço Redondo, Porto da Folha, Carira e Nossa Senhora de Aparecida; na mesorregião do agreste os municípios de Tobias Barreto, Lagarto, Itabaiana, Nossa senhora das Dores e Aquidabã; na mesorregião do litoral os municípios de Japoatã, Japaratuba, São Cristóvão, Estância, Arauá e Itabaianinha.

Os municípios foram escolhidos de acordo com as localizações dentro de cada mesorregião do estado, para ter uma maior abrangência territorial e também de acordo com a sua importância na produção agropecuária do estado. Foram feitas visitas em 2 propriedades por município totalizando 32 propriedades que possuem como principal fonte de renda a pecuária, entre os anos de 2015 e 2016 . 0 protocolo da entrevista constou na entrega de formulários semelhantes aos empregados por Silva et al. (2006). Os três formulários foram aplicados a todos os entrevistados durante visita às propriedades. Além dos produtores foram entrevistados veterinários que realizam atendimentos nos municípios. Ao todo foram entrevistados 32 produtores e 10 Médicos Veterinários. Uma cartilha (Riet-Correa et al. 2011a) foi utilizada como material ilustrativo aos entrevistados para facilitar o reconhecimento das plantas tóxicas. As plantas que não estavam na lista da entrevista, que os produtores mencionaram como tóxicas, foram mencionadas separadamente.

\section{RESULTADOS}

Os entrevistados mencionaram 20 plantas tóxicas. Foram relatados, também, casos suspeitos de intoxicações por plantas que não estavam na lista descrita no questionário.
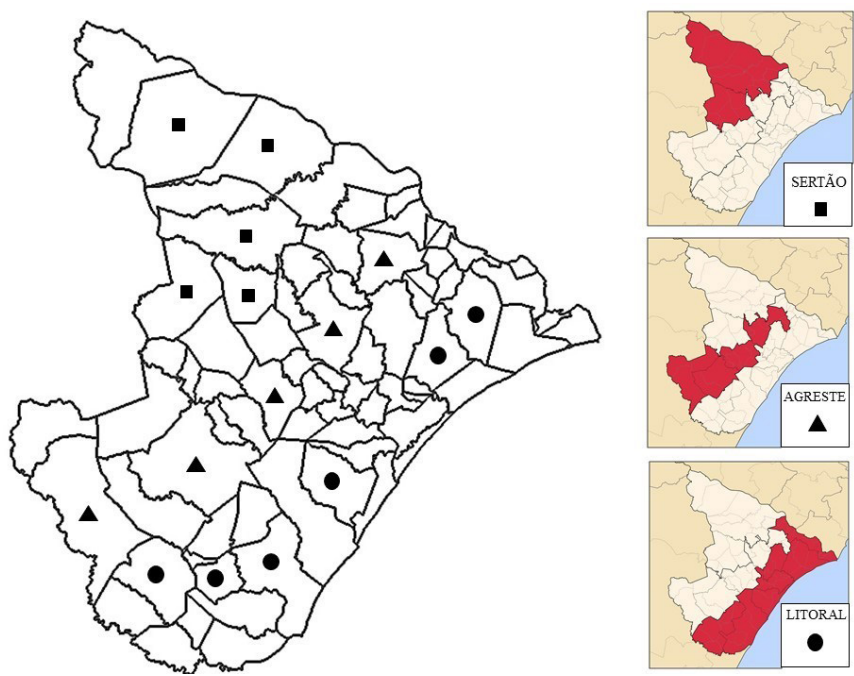

Fig.1. Mapa geográfico do estado de Sergipe mostrando as divisões das mesorregiões e municípios visitados marcados por símbolos.
Plantas que produtores relataram como sendo tóxicas Brachiaria decumbens (Capim braquiária). Capim difusamente difundido no estado, onde trinta e um dos entrevistados relataram problemas relacionados a lesões cutâneas. Pelo fato de ser um capim bastante utilizado no estado, a informação da sua toxicidade também é bastante divulgada, principalmente para ovinos. Os relatos são principalmente em animais que possuem a pele com áreas despigmentadas. Um criador do município de Tobias Barreto, relatou que de 6 ovinos da raça White Dopper, comprados no oeste da Bahia, 4 animais apresentaram problemas de descamação da pele na face e dorso após 3 meses de serem introduzidos na pastagem de B. decumbens. As outras duas espécies $B$. brizantha, $B$. humidicola também são mencionadas como tóxicas e provocam as mesmas lesões.

Ipomoea asarifolia (Salsa). Vinte e seis produtores reconheceram a planta como tóxica, e tinham presenciado intoxicações em ovinos, caprinos e bovinos. Os quadros são parecidos em todas as espécies. Na época de estiagem quando há diminuição da disponibilidade de forragem, os animas após se alimentarem da planta apresentam sinais de tremores musculares, andar cambaleante, incoordenação e episódios de quedas, que evoluem para decúbito permanente e morrem.

Amorimia spp. (Tingui). Planta comumente conhecida pelos produtores como "erva"; dezessete pessoas relacionaram a planta com quadros de morte súbita associada ao exercício. Os animais normalmente são encontrados mortos próximos a arbustos da planta e quando vivos demonstram relutância a se movimentar, quando forçados a se locomover rapidamente podem morrer. Ocorreram 13 relatos em bovinos e 4 em ovinos.

Ipomoea carnea subsp. fistulosa (Algodão-bravo). Dez produtores relataram problemas de intoxicação pela planta em suas propriedades. Dois relataram que os animais começaram a comer a planta na época de estiagem. Após as chuvas e o aumento da disponibilidade de forragem, poucos animais continuam comendo a planta com menor intensidade, sempre retornando a área onde ocorria a planta.

Aspidosperma pyrifolium (Pereiro). Dez produtores associaram abortos em pequenos ruminantesà ingestão tanto das folhas secas da planta caídas ao chão quanto, das folhas verdes. A maioria dos casos ocorreu na época de estiagem, quando as folhas caem e os animais tem acesso a uma quantidade considerável das mesmas. Em uma propriedade no município de Nossa Senhora das Dores, os abortos da criação de ovinos, geraram uma perda de 50\% dos nascimentos no ano de 2014, ano que a disponibilidade de pastagem foi prejudicada pela estiagem e os animais tiveram muito tempo pastando numa área com grande quantidade da planta.

Manihot esculenta (Macaxeira). Nove entrevistados relataram problemas relacionados à macaxeira. Um perdeu 4 bovinos que se alimentaram das cascas e partes da raiz da planta desprezadas por um restaurante. Os pedaços foram ofertados diretamente ao cocho no dia após a colheita e processamento. Um produtor relatou um caso em um caprino após a ingestão do resíduo líquido (manipueira) resultante do beneficiamento da mandioca. Todos os animais, ao se alimentar de partes da planta, das cascas e do líquido da planta morreram rapidamente após a ingestão.

Pennisetum purpureum (Capim elefante). Oito produtores relataram problemas com essa espécie de capim. Dois afirmaram que equinos alimentados com capim triturado 
na forrageira, desenvolveram cólica por compactação. Segundo os produtores o capim estava muito seco, passado do ponto de corte, ou a forrageira estava desregulada cortando pedaços muito pequenos. Um produtor relatou a morte de duas vacas leiteiras que foram alimentadas com o capim na fase inicial de crescimento. 0 capim foi retirado de um plantio após uma adubação com esterco de ovino e era irrigado com a água decorrente da lavagem da sala de ordenha e curral.

Poiretia punctata (Pela bucho). Foi relatada por oito produtores como responsável de causar mortes em ovinos e bovinos. Um dos produtores relatou um surto em 2015 com a morte de 4 ovinos de um lote de 16 animais em fase final de engorda que tinham sido recentemente transferidos para um piquete com áreas sombreadas próximo ao rio. Somente depois da morte dos animais foi feita uma investigação no piquete constatando-se a presença de $P$. punctata. Todos os animais foram encontrados mortos e sem apresentar nenhum sinal clínico nos dias anteriores. Na necropsia observou-se carcaça distendida por gás e epitélio ruminal descamando facilmente, o que da o nome popular de "pela bucho" essas lesões são características de autólise. Frequentemente os animais morrem subitamente e só são vistos horas após a morte. A toxicidade de esta planta foi testada experimentalmente reproduzindo-se sinais clínicos semelhantes aos descritos pelos produtores (Nascimento et al. 2014).

Palicourea aeneofusca (Erva de rato). É conhecida popularmente na região com "erva verdadeira". Seis produtores relataram morte súbita associada ao exercício em bovinos. O diagnóstico presuntivo foi pela observação de partes da planta consumidas e a ausência de lesões macroscópicas. Todos os relatos foram descritos na mesorregião do litoral.

Mimosa tenuiflora (Jurema preta). A planta é suspeita de ter causado malformações em caprinos e ovinos no estado. Seis entrevistados observaram que animais que pastavam em áreas com a planta em quantidade abundante, tiveram nascimento de animais com malformações. Um produtor relatou que dois animais morreram com problemas no parto, por não conseguir expulsar os fetos malformados.

Crotalaria retusa (Guiz de cascavel). Cinco entrevistados afirmaram ter casos suspeitos de intoxicação por C. retusa. Todos os casos foram relacionados a equinos que tinham pastejado áreas infestadas da planta por períodos entre 30 e 50 dias. Clinicamente apresentaram emagrecimento, alterações na marcha, ascite e sinais nervosos.

Cnidoscolus quercifolius (Favela). Três produtores relataram problemas com a planta. Um relatou problema com a planta recém-colhida e triturada em máquina forrageira junto com capim elefante (Pennisetum purpureum) que foi ofertada para 4 vacas leiteiras criadas confinadas, ocasionando a morte de 2 animais. Outros 2 produtores foram aconselhados por um prático a cortar e reservar a planta à sombra por 3 dias, pois fazendo isso, a planta iria perder a toxicidade. A planta após esse manejo foi adicionada a palha de milho e ofertado no cocho, com o intuito de enriquecer nutricionalmente o volumoso do rebanho. Mesmo com o manejo aconselhado foram relatados problemas e perdas de ovinos.

Enterolobium contortisiliquum (Orelha de macaco). Três proprietários relacionaram a planta a problemas digestivos em bovinos associados com a presença de inúmeras sementes nas fezes. Os animais apresentaram um quadro de diarreia que perdurou entre 2 e 4 dias. Dois proprietários do município de Aquidabã relataram problemas. Um informou que, após a derrubada de uma árvore, 3 ovinos se alimentaram das folhas da planta e desenvolveram um quadro agudo de timpanismo e dois morreram.

Prosopis juliflora (Algarroba). Trinta e nove dos quarenta e dois entrevistados informaram que sempre notaram os animais alimentando-se das vagens que caem ao chão. Afirmaram ainda que reconhecem a as vagens da planta são tóxicas, e que sua utilização no cocho para a alimentação animal deve ser controlada, não se chegando a um consenso de quantidade e tempo de administração. Somente 2 entrevistados relataram problemas. Um suspeitou de que as vagens da algarroba causaram problemas em ovinos. Outro produtor relatou que após fornecer vagens de algarroba por 4 meses a uma vaca, no período de estiagem, notou que a mesma apresentou problema de mastigação, deglutição, atrofia de musculatura da mandíbula e perda de peso progressiva

Panicum maximum (Capim mombaça). Dois produtores relataram que esse capim foi o responsável por causar problemas digestivos em bovinos. Um relatou que 2 animais morreram por intoxicação causada pelo capim. 0 lote era constituído por 17 vacas, da raça girolando, todas em lactação. Os animais eram criados em piquetes rotacionados do capim e suplementados uma vez ao dia com ração comercial balanceada para bovinos a $1 \%$ de peso vivo. Um piquete que ficava ao lado do curral recebeu toda a drenagem e material do curral após um curto período chuvoso durante a estação seca, obtendo um crescimento superior os outros piquetes, superando o crescimento de $2 \mathrm{~cm}$ por dia. Dois animais desse lote ultrapassaram a cerca que isolava os piquetes e invadiram o piquete que apresentava essa forragem verde e viçosa, os animais só foram notados que tinham invadido o piquete 1 hora e meia após a soltura do lote no piquete correto. Os animais já foram encontrados em decúbito lateral, com timpanismo acentuado morrendo antes do atendimento veterinário, certa de 2 horas após a observação dos sinais clínicos. Outro produtor relatou que 4 animais ficaram doentes e 2 morreram. Os sinais digestivos foram de timpanismo e diarreia e as mortes aconteceram em questão de horas. Os dois produtores possuíam áreas adubadas e irrigadas, onde estavam fechadas e os animais invadiram o cercado e tiveram acesso ao capim que ainda estava em rebrota.

Anadenanthera colubrina (Angico preto). Vinte e nove entrevistados relataram a ocorrência da planta, porém, somente um produtor no município de Lagarto, associou a planta a um surto de intoxicação que ocorreu quando uma árvore foi podada e os galhos ficaram ao chão. Um caprino, que estava sendo criado sozinho, como animal de estimação, isolado do rebanho, após ingerir às folhas da planta apresentou tremores, convulsão e morte rápida. Muitos entrevistados não reconheceram $A$. colubrina como planta tóxica, e afirmaram que a casca da árvore é usada na medicina alternativa humana.

Nerium oleander (Espirradeira). Trinta e cinco entrevistados responderam que conheciam a planta e por ser uma planta ornamental não observaram casos de intoxicação em suas propriedades. Somente um veterinário relatou que após a poda das árvores realizada pela prefeitura no município de Japaratuba, quatro animais que pastejavam nos lixões da cidade, tiveram acesso a espirradeira e morreram no mesmo dia que a planta foi despejada no lixão. Na necropsia 
observaram-se lesões hemorrágicas em diversos órgãos e a presença da planta no rumem dos animais.

Tephrosia cinerea (Falso anil). Um veterinário responsabilizou a planta por um surto no município de Aquidabã, no que 4 ovinos morreram com sinais de apatia e distensão abdominal. Na necropsia de um dos animais observou uma marcada ascite e lesões hepáticas (fibrose). Na propriedade havia uma área próximaa ao rio com uma grande quantidade da planta.

Produtores relataram duas plantas (Ziziphus joazeiro e Citrus sp.) como responsáveis como tóxica, porém não há comprovação científica de intoxicações.

Ziziphus joazeiro (Juazerio). Um produtor relatou que no município de Poço Redondo, na época de estiagem o rebanho com 21 caprinos, jovens e adultos de ambos os sexos, criados semi-extensivamente, eram soltos pela manhã e recolhidos ao aprisco no fim do dia. Ao serem transferidos para uma pastagem com várias árvores de juazeiro em época de frutificação, 2 animais jovens adoeceram pela ingestão dos frutos maduros que estavam no chão. Os dois animais após o dia de pastejo na área, não retornaram para o aprisco ao fim da tarde observou-se os animais na pastagem, um animal com leve timpanismo, salivação, relutância em se locomover demonstrando desconforto abdominal e apatia que após tratamento obteve melhora. Outro animal apresentou timpanismo acentuado, decúbito esternal, ausência de fezes, relutância a se movimentar, salivação e apatia mesmo após tratamento não se obteve melhora, morrendo no dia seguinte ao aparecimento dos sinais clínicos. Na necropsia observou-se uma grande quantidade de sementes da planta compactando os pré-estômagos.

Citrus sp. (Laranja). A casca de laranja é um subproduto das usinas de beneficiamento muito comum utilizado na alimentação de bovinos confinados no estado. Um produtor no município de Lagarto, relatou que 4 bovinos invadiram a área onde se armazenava o produto. Após ingerir as cascas apresentaram leve timpanismo, diminuição da ruminação e perda de equilíbrio, se recuperando entre 8 e 12 horas após a retirada dos animais dessa área.

\section{DISCUSSÃO}

Algumas plantas que alteram funcionamento hepático foram citadas pelos produtores. 0 capim Brachiaria foi a planta mais relacionada a intoxicações afetando preferencialmente ovinos. Dentre as espécies os bovinos são mais resistentes que os ovinos e em relação à idade os animais jovens são mais susceptíveis (Souza et al. 2010, Riet-Correa et al. 2011b). A introdução de animais em pastagens de Brachiaria spp. deve ser gradativa e com avaliação constante dos animais. Acredita-se que os ovinos criados em pastagens de Brachiaria spp. podem ser mais resistentes as intoxicações do que os criados em outras pastagens (Aniz 2008, Castro et al. 2011).

As plantas cianogênicas apontadas pelos produtores Manihot spp., Anadenanthera colubrina e Cnidoscolus quercifolius como causa de mortes após um curso clínico superagudo. Nas intoxicações os entrevistados relataram que os animais só se intoxicaram acidentalmente, ao ter acesso às folhas da planta e ao subproduto da mandioca. Estas condições já foram relatadas anteriormente (Riet-Correa et al. 2006b). Para confirmação do diagnóstico deve-se utilizar o teste do papel picrosódico (Amorim et al. 2005). Deve-se fazer o diagnóstico diferencial com intoxicações por outras plantas, incluindo a intoxicação por Amorimia septentrionalis (Tokarnia et al. 2012) e a intoxicação por nitritos e nitratos (Medeiros et al. 2003).

As plantas relacionadas com morte súbita pelos entrevistados foram Amorimia spp., Palicourea aeneofusca e Poiretia punctata. As duas primeiras possuem como principio tóxico o monofluoracetato e causam grandes perdas aos produtores por morte de animais (Tokarnia et al. 2012). Porém, o diagnóstico confirmatório quase sempre é epidemiológico, associando a presença da planta e a ocorrência de morte súbita de animais associadas ao exercício, fazendo com que quase nunca o veterinário seja chamado para confirmação do diagnóstico. Amorimia septentrionalis é a planta mais importante para o nordeste (Tokarnia et al. 2012). Poiretia punctata demonstrou ser uma planta que causa morte súbita em bovinos e ovinos na mesorregião do litoral. Os animais frequentemente são achados mortos na pastagem e com moderado grau de autólise (Nascimento et al. 2014) semelhante ao descritos pelos produtores neste trabalho.

Em relação à Crotalaria retusa, todos os produtores relacionaram intoxicações somente em equinos. Porém a intoxicação pode ocorrer não só em equinos, mas também em ovinos e bovinos (Nobre et al. 2005).

E relação ao problema ocorrido por causa do Panicum maximum, quadros de intoxicações semelhantes foram relatados em equinos causando cólica, após a transferência de animais para pastagem composta por esse capim (Schons et al. 2012). Em bovinos, quadros caracterizados por timpanismo agudo espumoso, são característicos de plantas que provocam fermentação excessiva, sendo pobres em fibra, com altos teores de carboidratos solúveis e proteína. Geralmente são plantas de crescimento rápido e em brotação e ainda apresentam alto teor de água (Dirksen et al. 1993, Jones et al. 1997). No Brasil casos de timpanismo espumoso foram relatados em bovinos semiconfinados em pastagens de Trifolium pratense (Dalto et al. 2009).

Produtores relatam que a casca da laranja deve passar por um processo de descanso antes de ser consumida. Deve-se espalhar a poupa numa área ventilada e esperar 2 dias para o fornecimento para o gado. Sinais semelhantes aos mencionados por produtores na intoxicação por poupa de laranja foram descritos na intoxicação por etanol produzido pela fermentação de Anacardium occidentale (pseudo-fruto do cajueiro) quando bovinos naturalmente se alimentaram dos pseudo-frutos fermentados (Soto-Blanco \& Ribeiro Filho 2007)

Muitos produtores mencionaram casos de intoxicação, relacionando os achados epidemiológicos e clínicos. Este trabalho aporta informação relevante sobre ocorrência das intoxicações por plantas no estado de Sergipe, o que permite recomendar medidas de profilaxia e controle das intoxicações.

\section{REFERÊNCIAS}

Amorim S.L., Medeiros R.M.T. \& Riet-Correa F. 2005. Intoxicação experimental por Manihot glaziovii (Euphorbiaceae) em caprinos. Pesq. Vet. Bras. 25(3):179-187. http://dx.doi.org/10.1590/S0100-736X2005000300009.

Aniz A.C.M. 2008. Efeito da adaptação ao consumo de Brachiaria decumbens e a existência de resistência ou susceptibilidade individual em ovinos à intoxicação. Monografia, Universidade Federal de Mato Grosso do Sul, Campo Grande. 31p.

Castro M.B., Santos Junior H.L., Mustafa V.S., Gracindo C.V., Moscardini A.C.R., Louvandini H., Paludo G.R., Borges J.R.J., Haraguchi M., Ferreira M.B. \& Riet-Correa F. 2011. Brachiaria spp. poisoning in sheep in Brazil: 
experimental and epidemiological findings, p.110-117. In: Riet-Correa F., Pfister J., Schild A.L. \& Wierenga T. (Eds), Poisoning by Plants, Mycotoxins and Related Toxins. CAB International, Willingford.

Dalto A.G.C., Bandarra P.M., Pedroso P.M.O., Guagnini F.S., Leal J.S., Raymundo D.L. \& Driemeier D. 2009. Timpanismo espumoso em bovinos leiteiros em pastagens de Trifolium spp. (Leg. Caesalpinoideae). Pesq. Vet. Bras. 29(5):401-403. http://dx.doi.org/10.1590/S0100-736X2009000500007.

Dirksen G., Gründer H.-D. \& Stöber M. 1993. Rosenberger, Exame Clínico dos Bovinos. 3aㅡ ed. Guanabara Koogan, Rio de Janeiro, p.166-228.

Jones T.C., Hunt R.D. \& King N.W. 1997. Patologia Veterinária. 6ª ed. Manole, Barueri.

Medeiros R.M.T., Barbosa R.C., Riet-Correa F., Lima E.F., Tabosa I.M., Barros S.S., Gardner D.R. \& Molyneux R.J. 2003. Tremorgenic syndrome in goats caused by Ipomoea asarifolia. Toxicon 41(7):933-935. http://dx.doi. org/10.1016/S0041-0101(03)00044-8. PMid:12782095.

Nascimento E.M., Medeiros R.M.T., Lee S.T. \& Riet-Correa F. 2014. Poisoning by Poiretia punctata in cattle and sheep. Pesq. Vet. Bras. 34(10):963-966. http://dx.doi.org/10.1590/S0100-736X2014001000007.

Nobre V.M.T., Dantas A.F.M., Riet-Correa F., Barbosa Filho J.M., Tabosa I.M. \& Vasconcelos J.S. 2005. Acute intoxication by Crotalaria retusa in sheep. Toxicon 45(3):347-352. http://dx.doi.org/10.1016/j.toxicon.2004.11.005. PMid:15683873.

Pessoa C.R.M., Medeiros R.M.T. \& Riet-Correa F. 2013. Importância econômica, epidemiologia e controle das intoxicações por plantas no Brasil. Pesq. Vet. Bras. 33(6):752-758. http://dx.doi.org/10.1590/S0100-736X2013000600011.

Riet-Correa F. \& Medeiros R.M.T. 2001. Intoxicações por plantas em ruminantes no Brasil e no Uruguai: importância econômica, controle e riscos para a saúde pública. Pesq. Vet. Bras. 21(1):38-42. http://dx.doi.org/10.1590/ S0100-736X2001000100008.
Riet-Correa F., Bezerra C.W.C. \& Medeiros R.M.T. 2011a. Plantas Tóxicas do Nordeste. Sociedade Vicente Pallotti, Patos, p.12-75.

Riet-Correa B., Castro M.B., Lemos R.A., Riet-Correa G., Mustafa V. \& Riet-Correa F. 2011b. Brachiaria spp. poisoning of ruminants in Brazil. Pesq. Vet. Bras. 31(3):183-192. http://dx.doi.org/10.1590/S0100-736X2011000300001.

Riet-Correa F., Medeiros R.M.T. \& Dantas A.F. 2006a. Plantas Tóxicas da Paraíba. SEBRAE, João Pessoa, p.9-54.

Riet-Correa F., Medeiros R.M.T. \& Dantas A.F. 2006b. Plantas Tóxicas da Paraíba. SEBRAE, João Pessoa. p.9-58.

Riet-Correa F., Pfister J., Schild A.L., Medeiros R.M. \& Dantas A.F.M. 2009. Poisoning by Plants, Mycotoxins and Related Substances in Brazilian Livestock. Santa Pallotti, Santa Maria, p.2-25.

Schons S.V., Lopes T.V., Melo T.L., Lima J.P., Riet-Correa F., Barros M.A.B. \& Schild A.L.P. 2012. Intoxicações por plantas em ruminantes e equídeos na região central de Rondônia. Ciência Rural 42(7):1257-1263. http://dx.doi. org/10.1590/S0103-84782012005000047.

Silva D.M., Riet-Correa F., Medeiros R.M.T. \& Oliveira O.D. 2006. Plantas tóxicas para ruminantes e equídeos no Seridó Ocidental e Oriental do Rio Grande do Norte. Pesq. Vet. Bras. 26(4):223-236. http://dx.doi.org/10.1590/ S0100-736X2006000400007.

Soto-Blanco B. \& Ribeiro Filho M. 2007. Intoxicação pelo pseudo-fruto do cajueiro (Anacardium occidentale L.) em bovinos. Anais VII Congresso Brasileiro de Buiatria, Curitiba. (CD-Rom)

Souza R.I.C., Riet-Correa F., Brum K.B., Fernandes C.E., Barbosa-Ferreira M. \& Lemos R.A.A. 2010. Intoxicação por Brachiaria spp. em bovinos no Mato Grosso do Sul. Pesq. Vet. Bras. 30(12):1036-1042. http://dx.doi. org/10.1590/S0100-736X2010001200006.

Tokarnia C.H., Brito M.F., Barbosa J.D., Peixoto P.V. \& Döbereiner J. 2012. Plantas Tóxicas do Brasil para Animais de Produção. $2^{\mathrm{a}}$ ed. Helianthus, Rio de Janeiro, p.1-464. 